\title{
Health care disparities in colorectal and esophageal cancer
}

\author{
Francisco Schlottmann a, b, *, Charles Gaber ${ }^{\text {a, c }}$, Paula D. Strassle ${ }^{\text {a, c }}$, Anthony G. Charles a , \\ Marco G. Patti ${ }^{\text {a, d }}$ \\ a Department of Surgery, University of North Carolina, Chapel Hill, NC, USA \\ ${ }^{\mathrm{b}}$ Department of Surgery, Hospital Alemán of Buenos Aires, Buenos Aires, Argentina \\ ${ }^{c}$ Department of Epidemiology, Gillings School of Global Public Health, University of North Carolina at Chapel Hill, Chapel Hill, NC, USA \\ d Department of Medicine, University of North Carolina, Chapel Hill, NC, USA
}

\section{A R T I C L E I N F O}

Article history:

Received 27 May 2019

Received in revised form

16 December 2019

Accepted 19 December 2019

Keywords:

Esophageal cancer

Colorectal cancer

Disparities

\begin{abstract}
A B S T R A C T
Background: We aimed to identify differences in disparities among patients with a cancer in which screening is widely recommended (colorectal cancer [CRC]) and one in which it is not (esophageal cancer).

Methods: A retrospective analysis was performed using 2004-2015 data from the National Cancer Database. Multivariable generalized logistic regression was used to identify potential differences in the effect of disparities in stage at diagnosis.

Results: A total of 96,524 esophageal cancer patients and 361,187 CRC patients were included. Black patients, longer travel distances, and lower educational attainment were only associated with increased odds of stage IV CRC. While both Medicaid and uninsured patients were more likely to be diagnosed with stage IV esophageal and CRC, the effect was larger among CRC patients. From 2004 to 2015, the rates of stage IV esophageal cancer decreased from $42.0 \%$ to $38.2 \%$, while the rates of stage IV CRC increased from $36.9 \%$ to $40.8 \%(\mathrm{p}<0.0001)$.

Conclusions: Disparities are more pronounced in CRC, compared to esophageal cancer. Equity in access to screening and cancer care should be prioritized.
\end{abstract}

\section{Introduction}

Cancer is a global public health problem and is the second leading cause of death in the United States (US). ${ }^{1}$ Despite remarkable medical advances in early diagnosis and treatment of several cancer types, racial and socioeconomic inequalities persist in cancer survival. ${ }^{2,3}$ Unequal access to care and inadequate health care utilization are the main determinants of these disparities. ${ }^{4,5}$

Colorectal cancer (CRC) is the third most common cancer in both men and women in the US, with approximately 135,430 individuals newly diagnosed and 50,260 deaths from the disease in $2017 .{ }^{6}$ Esophageal cancer is less frequent in the US, with approximately 16,940 new cases and 15,690 deaths in 2017 . $^{7}$ However, the incidence of esophageal adenocarcinoma is expected to increase substantially in the US because of the rising prevalence of obesity and gastroesophageal reflux disease. ${ }^{8,9}$ Both CRC and esophageal cancer have poor prognoses when diagnosed at stage IV with distant

\footnotetext{
* Corresponding author. University of North Carolina at Chapel Hill 101, Manning Drive, CB 7081, Chapel Hill, NC, 27599-7081, USA.

E-mail address: fschlottmann@hotmail.com (F. Schlottmann).
}

metastases (5-year survival rates of $13.9 \%$ and $4.6 \%$, respectively). ${ }^{7,10}$

The purpose of this analysis was to assess whether the effects of disparities on stage of diagnosis differ across patients with a cancer in which screening is recommended (CRC), compared to one with no such recommendation (esophageal cancer). We hypothesized that disparities would be amplified in cancers in which screening is available and widely recommended.

\section{Methods}

A cohort of patients was identified using the National Cancer Database (NCDB) between January 1, 2004 and December 31, 2015. The NCDB is a national hospital-based cancer registry program implemented by the Commission on Cancer of the American College of Surgeons and the American Cancer Society. The database includes over 1500 hospitals and obtains close to $70 \%$ of incident cancer cases in the US.

Adult patients ( $\geq 18$ years old) with a diagnosis of esophageal cancer or CRC were eligible for inclusion. Stage of cancer at diagnosis was ascertained using the TNM staging system of the American Joint Commission of Cancer (AJCC). Patients with missing age 
or missing TNM staging data were excluded from the analysis.

\section{Statistical analysis}

Patient demographics and cancer characteristics for patients with both esophageal cancer and CRC were reported using descriptive statistics. Yearly rates in stage at diagnosis, stratified by cancer type, were assessed using Poisson regression.

Multivariable generalized logistic regression was used to assess whether the impact of race, residential income, travel distance (categorized into quartiles), primary insurance, and education on the odds of having a cancer diagnosed at each stage relative to stage I (outcome reference category) differed between patients with esophageal cancer and CRC. Both educational attainment, defined as the percentage of adults in a given patient's ZIP code who did not graduate from high school and split into quartiles, and residential income, defined as the median household income in the ZIP code of a patient's residence and split into quartiles, were derived from the linked 2012 American Community Survey. Travel distance, reported as the distance between centroid of the patient's zip code and the address of their primary cancer care hospital, was also split into quartiles for analysis. Interaction terms between cancer type (esophageal cancer vs. CRC) and each disparity and likelihood ratio tests were used to determine whether the effect on stage at diagnosis was significantly different between the two cancers. The model was also adjusted for patient age (modeled as a restricted cubic spline), sex, Charlson-Deyo comorbidity score, and year of diagnosis.

Finally, we performed a sensitivity analysis restricting the cohort to ages in which screening for CRC is mostly recommended, including CRC patients $\geq 50$ years old.

A p-value $<0.05$ was considered significant for all the statistical methods.

All analyses were performed using SAS software version 9.4 (SAS Inc., Cary, NC).

\section{Results}

A total of 96,524 esophageal cancer patients and 361,187 CRC patients were included. Stage IV at diagnosis was present in $39 \%$ of the esophageal cancer patients, and in 35\% of the CRC patients. Patient characteristics, stratified by stage at diagnosis, for esophageal and CRC cancer are described in Tables 1 and 2, respectively. Between 2004 and 2015, the number of esophageal cancers diagnosed at stage I increased from $10.2 \%$ to $13.1 \%$, while the number diagnosed at stage IV decreased from $42.0 \%$ to $38.2 \%$, p $<0.0001$ (Fig. 1). For CRC, the number of cancers diagnosed at stage I remained relatively constant from $26.3 \%$ to $26.7 \%$, but the number diagnosed at stage IV increased from $36.9 \%$ to $40.8 \%$, p $<0.0001$ (Fig. 2).

Race

Among patients with esophageal cancer, black patients were more likely to be diagnosed with stage III cancer (OR 1.25, 95\% CI $1.15,1.37$ ), compared to stage I, and other race patients were more likely to be diagnosed with both stage II $(1.20,95 \%$ CI $1.02,1.42)$ and stage III (OR 1.44, 95\% CI 1,22, 1.69); however, no difference in the odds of stage IV diagnoses were seen (OR 1.04, 95\% CI 0.96, 1.13, and OR $1.11,95 \%$ CI 0.95, 1.30 , respectively) (Table 3 ).

In patients with CRC, both black and other race patients were more likely to be diagnosed with stage III (OR 1.06, 95\% CI 1.03, 1.10 and OR $1.14,95 \%$ CI 1.08, 1.20) and stage IV (OR 1.34, 95\% CI 1.30, 1.37 and OR 1.04, 1.00,1.10) disease, although the association between other race and stage IV disease was minimal. The effect of race on stage at diagnosis was significantly different between esophageal cancer and CRC patients, $\mathrm{p}<0.0001$.

\section{Primary insurance}

When compared to patients with private insurance, Medicaid and uninsured patients had higher odds of both stage III (OR 1.20, 95\% CI 1.08, 1.33 and OR 1.53, 95\% CI 1.31, 1.78) and stage IV esophageal cancer (OR 1.34, 95\% CI 1.21, 1.47 and OR 1.99, 95\% CI $1.72,2.31$, respectively). Patients with Medicaid and those uninsured were also more likely to be diagnosed with stage II (OR 1.44, 95\% CI 1.37, 1.51 and OR 2.05, 95\% CI 1.92, 2.17), stage III (OR 1.44, 95\% CI 1.37, 1.52 and OR 1.90, 95\% CI 1.78, 2.02), and stage IV (OR $1.94,95 \%$ CI 1.86, 2.02 and OR 1.22, 95\% CI 2.21, 2.46) CRC, although the magnitude of the effects were more pronounced ( $\mathrm{p}<0.0001$ ). Interestingly, patients with Medicare were significantly less likely to be diagnosed with stage II, stage III, and stage IV esophageal disease, whereas Medicare patients with CRC were slightly more likely to be diagnosed with more advanced stages (Table 3).

\section{Travel distance}

Among patients diagnosed with esophageal cancer, travel distance had an inverse impact on the odds of being diagnosed with advanced disease. Patients who were $\geq 18$ miles from their cancer center were significantly less likely to be diagnosed with stage II (OR 0.78, 95\% CI 0.73, 0.83), stage III (OR 0.79, 95\% CI 0.74, 0.84), and stage IV (OR 0.50, 95\% CI 0.47, 0.53) disease; moreover, across all increased travel distances, a decreased odds of stage IV diagnosis was observed (Table 3).

Travel distance had minimal impact on stage at diagnosis after adjustment in patients with CRC; however, patients who were $\geq 18$ miles from their cancer center were significantly more likely to be diagnosed with stage IV cancer (OR 1.20, 95\% CI 1.17, 1.23). The effect of travel distance on stage at diagnosis was also significantly different across cancer type, $\mathrm{p}<0.0001$.

\section{Residential income}

Median residential income also had minimal impact on the odds of advanced disease diagnoses across both esophageal cancer and CRC, and the effect of income on stage at diagnosis was relatively consistent across CRC and esophageal cancer (Table 3).

\section{Education}

Education level of a patient's zip code had no meaningful impact on the stage of diagnosis in esophageal cancer (Table 3 ). However, that was not the case for CRC. Patients living in areas where $\geq 7 \%$ of adults did not complete high school were fairly consistently more likely to be diagnosed with stage II, stage III, and stage IV disease. Unsurprisingly, the effect of education on stage at diagnosis was also differential across cancer type $(\mathrm{p}=0.002)$.

\section{Disparities in CRC patients $\geq 50$ years old}

When restricting the cohort to ages in which screening for CRC is mostly recommended, we found similar results. Black patients were more likely to be diagnosed with stage IV cancer. Compared to patients with private insurance, Medicaid, Medicare, and uninsured patients had higher odds of being diagnosed with stage IV cancer. Similarly, patients living in areas where $\geq 7 \%$ of adults did not complete high school were more likely to be diagnosed with stage IV disease (Appendix Table). 
Table 1

Distribution of patient characteristics among patients diagnosed with esophageal cancer, stratified by stage at diagnosis, $\mathrm{n}=96,524$

\begin{tabular}{|c|c|c|c|c|}
\hline & $\begin{array}{l}\text { Stage I } \\
\mathrm{N}=12,637(13 \%)\end{array}$ & $\begin{array}{l}\text { Stage II } \\
\mathrm{N}=23,965(25 \%)\end{array}$ & $\begin{array}{l}\text { Stage III } \\
N=22,620(23 \%)\end{array}$ & $\begin{array}{l}\text { Stage IV } \\
\mathrm{N}=37,302(39 \%)\end{array}$ \\
\hline Age in years, mean (SD) & $68.9(11.4)$ & $67.5(11.2)$ & $65.6(11.1)$ & $64.8(11.7)$ \\
\hline Male, n (\%) & $9701(76.8)$ & $18,562(77.5)$ & $17,714(78.3)$ & $30,540(81.9)$ \\
\hline \multicolumn{5}{|l|}{ Race, n (\%) } \\
\hline White & $11,264(90.7)$ & $21,193(89.3)$ & $19,465(86.9)$ & $32,328(87.5)$ \\
\hline Black & $929(7.5)$ & $1992(8.4)$ & $2308(10.3)$ & $3767(10.2)$ \\
\hline Other & $227(1.8)$ & $549(2.3)$ & $616(2.8)$ & $872(2.4)$ \\
\hline \multicolumn{5}{|c|}{ Charlson comorbidity score } \\
\hline 0 & $8905(70.5)$ & $17,216(71.8)$ & $16,844(74.5)$ & 27,547 (73.9) \\
\hline 1 & $2675(21.2)$ & $4971(20.7)$ & 4455 (19.7) & $7213(19.3)$ \\
\hline 2 & $731(5.8)$ & $1300(5.4)$ & $965(4.3)$ & $1802(4.8)$ \\
\hline$\geq 3$ & $326(2.6)$ & $478(2.0)$ & $356(1.6)$ & $749(2.0)$ \\
\hline \multicolumn{5}{|l|}{ Primary insurance, n (\%) } \\
\hline Private & $3729(30.7)$ & 7667 (33.5) & 7857 (36.7) & $13,205(36.8)$ \\
\hline Medicaid & $587(4.8)$ & $1366(6.0)$ & $1644(7.7)$ & $3168(8.8)$ \\
\hline Medicare & $7592(62.6)$ & $13,303(58.1)$ & $11,116(51.9)$ & $17,709(49.4)$ \\
\hline Uninsured & $226(1.9)$ & $545(2.4)$ & $805(3.8)$ & $1788(5.0)$ \\
\hline \multicolumn{5}{|l|}{ Travel distance } \\
\hline$<4$ miles & $2275(18.3)$ & $4906(20.8)$ & 4459 (20.1) & 9093 (24.9) \\
\hline 4-7.9 miles & $2100(16.9)$ & 4407 (18.7) & $4055(18.3)$ & $7628(20.9)$ \\
\hline 8-17.9 miles & $2669(21.4)$ & $5385(22.8)$ & $5125(23.1)$ & $8845(24.2)$ \\
\hline$\geq 18$ miles & $5404(43.4)$ & $8898(37.7)$ & $8537(38.5)$ & $10,998(30.1)$ \\
\hline \multicolumn{5}{|l|}{ Residential income } \\
\hline$<\$ 38,000$ & $2118(17.0)$ & 4151 (17.6) & $4104(18.5)$ & $6971(19.1)$ \\
\hline$\$ 38,000-\$ 47,999$ & $3057(24.6)$ & $5737(24.3)$ & $5436(24.5)$ & $9155(25.1)$ \\
\hline$\$ 48,000-\$ 62,999$ & $3443(27.7)$ & $6461(27.4)$ & $5856(26.4)$ & 9757 (26.7) \\
\hline$\geq \$ 63,000$ & $3823(30.7)$ & $7222(30.6)$ & $6766(30.5)$ & $10,671(29.2)$ \\
\hline \multicolumn{5}{|l|}{ Education $^{\mathrm{b}}, \mathrm{n}(\%)$} \\
\hline$<7 \%$ & 2978 (23.9) & $5666(24.0)$ & $5097(23.0)$ & $8151(22.3)$ \\
\hline $7-12.9 \%$ & $4359(35.0)$ & $8212(34.8)$ & 7468 (33.7) & $12,387(33.9)$ \\
\hline $13 \%-20.9 \%$ & $3293(26.5)$ & $6159(26.1)$ & $5876(26.5)$ & $9849(26.9)$ \\
\hline$\geq 21 \%$ & $1817(14.6)$ & $3551(15.1)$ & $3735(16.8)$ & $6183(16.9)$ \\
\hline
\end{tabular}

\section{Discussion}

In this study, we sought to assess whether the impact of disparities on the stage at diagnosis among patients with a cancer that has established screening guidelines, recommendations, and mandates (CRC) differed from one in which screening guidelines are not clearly established nor recommended (esophageal cancer). We found that disparities primarily existed for CRC only, and were more pronounced when compared to patients with esophageal cancer.

Previous studies have documented disparities in CRC survival by race and ethnicity. ${ }^{11-14}$ Arshad et al. ${ }^{13}$ found that among black patients, $40.9 \%$ presented with stage IV CRC, as compared to $25 \%$ of non-Hispanic whites. Ellis and colleagues ${ }^{14}$ previously stated that stage at diagnosis had the greatest influence on overall racial/ethnic survival disparities. We also found that black patients were significantly more likely to have advanced CRC. Interestingly, we did not find racial disparities in esophageal cancer. This observed difference may be attributable to the variations in the carcinogenic mechanisms and genetic factors among black adults with CRC. ${ }^{15}$ However, inadequate access to screening and earlier detection is also likely a major contributing factor. Some studies have reported a greater overall distrust of the healthcare system amongst black patients, which reduces the likelihood of seeking medical care. ${ }^{16,17}$ Thus, increasing medical trust and healthcare utilization by black patients may help decrease the evident racial disparities in CRC.

We also found that patients living in areas with higher median residential incomes were slightly less likely to be diagnosed with advanced stages of both esophageal cancer and CRC. Lower income has also associated with increased risk of stage IV cancer in previous studies. ${ }^{18,19}$ Travel burden appears to play an important role in disparities for screening-mandated cancers. In our study, longer distances between residence of patient and hospital were associated with increased odds of stage IV diagnosis only in CRC. Rural populations have been shown to have lower rates of localized stage cancer and higher rates of distant stage cancer among cancers with preventive opportunities. $^{20,21}$ Specifically, for CRC, Anderson et al. ${ }^{21}$ showed that rural vs. urban residence, travel time to the nearest colonoscopy provider, and spatial accessibility of providers were all significantly associated with adherence to screening guidelines. We also found that geographic proximity to cancer screening providers is a key factor contributing to cancer disparities in CRC. Interestingly, we also found that increased travel distances were inversely associated with stage of diagnosis among esophageal patients. Additional research is needed to assess this association and identify the potential causes.

Insurance status is a strong predictor of disparities in access and quality of cancer care. ${ }^{22}$ Uninsured individuals have shown higher rates of advanced disease and shorter overall survival in several cancer types. ${ }^{23-25}$ In our cohort, uninsured patients were also more likely to be diagnosed with stage IV in both esophageal cancer and CRC, although the magnitude of the effect was greater in CRC. Insurance coverage has been one of the major achievements of the Affordable Care Act (ACA). The number of uninsured Americans declined from 49 million in 2010 to 29 million in 2015 (uninsured rate dropped from $16.0 \%$ in 2010 to $9.1 \%$ in 2015). This is the largest decline in the uninsured rate since the implementation of Medicare and Medicaid in $1965 .^{26}$ The increase in number of insured patients was mostly due to Medicaid expansion. In fact, the uninsured rate dropped $36.3 \%$ in states that implemented the ACA's Medicaid expansion, compared with $23.9 \%$ in states without expansion. ${ }^{27}$ Increasing the number of persons with health insurance is commendable and can 
Table 2

Distribution of patient characteristics among patients diagnosed with colorectal cancer, stratified by stage at diagnosis, $\mathrm{n}=361,187$.

\begin{tabular}{|c|c|c|c|c|}
\hline & $\begin{array}{l}\text { Stage I } \\
N=101,786(28 \%)\end{array}$ & $\begin{array}{l}\text { Stage II } \\
N=72,879(20 \%)\end{array}$ & $\begin{array}{l}\text { Stage III } \\
\mathrm{N}=59,131(16 \%)\end{array}$ & $\begin{array}{l}\text { Stage IV } \\
N=127,391(35 \%)\end{array}$ \\
\hline Age in years, mean (SD) & $68.2(13.3)$ & $69.3(13.6)$ & $66.4(14.2)$ & $65.6(14.1)$ \\
\hline Male, n (\%) & $50,609(49.7)$ & $35,506(48.7)$ & $28,993(49.0)$ & $65,288(51.3)$ \\
\hline \multicolumn{5}{|l|}{ Race, n (\%) } \\
\hline White & $86,121(85.4)$ & $61,712(85.4)$ & $48,746(83.1)$ & $101,607(80.5)$ \\
\hline Black & $11,126(11.0)$ & $7927(11.0)$ & $7406(12.6)$ & $19,714(15.6)$ \\
\hline Other & $3582(3.6)$ & $2660(3.7)$ & $2500(4.3)$ & 4913 (3.9) \\
\hline \multicolumn{5}{|c|}{ Charlson comorbidity score } \\
\hline 0 & $70,503(69.3)$ & $50,139(68.8)$ & $42,455(71.8)$ & $93,456(73.4)$ \\
\hline 1 & $22,199(21.8)$ & $16,454(22.6)$ & $12,261(20.7)$ & $24,582(19.3)$ \\
\hline 2 & $6373(6.3)$ & $4519(6.2)$ & $3188(5.4)$ & $6321(5.0)$ \\
\hline$\geq 3$ & $2711(2.7)$ & $1767(2.4)$ & $1227(2.1)$ & $3032(2.4)$ \\
\hline \multicolumn{5}{|l|}{ Primary insurance, n (\%) } \\
\hline Private & $35,452(35.6)$ & $22,015(31.0)$ & $21,187(36.9)$ & $44,701(36.1)$ \\
\hline Medicaid & $3807(3.8)$ & $3428(4.8)$ & $3368(5.9)$ & $9763(7.0)$ \\
\hline Medicare & $58,177(58.5)$ & $42,973(60.5)$ & $30,439(53.0)$ & $62,951(50.8)$ \\
\hline Uninsured & $2058(2.1)$ & $2633(3.7)$ & $2409(4.2)$ & $6462(5.2)$ \\
\hline \multicolumn{5}{|l|}{ Travel distance } \\
\hline$<4$ miles & 28,163 (27.9) & $20,973(29.0)$ & $16,340(27.9)$ & $33,512(26.7)$ \\
\hline 4-7.9 miles & $23,883(23.6)$ & $16,949(23.5)$ & $13,516(23.1)$ & $27,894(22.3)$ \\
\hline $8-17.9$ miles & $25,450(25.2)$ & $17,498(24.2)$ & $14,562(24.9)$ & $29,937(23.9)$ \\
\hline$\geq 18$ miles & $23,577(23.3)$ & $16,824(23.3)$ & $14,078(24.1)$ & $34,037(27.2)$ \\
\hline \multicolumn{5}{|l|}{ Residential income ${ }^{a}$} \\
\hline$<\$ 38,000$ & $16,840(16.7)$ & $13,271(18.4)$ & $10,843(18.6)$ & $25,122(20.0)$ \\
\hline$\$ 38,000-\$ 47,999$ & $23,971(23.7)$ & $17,345(24.0)$ & $13,669(23.4)$ & $29,809(23.8)$ \\
\hline$\$ 48,000-\$ 62,999$ & $27,339(27.1)$ & $19,202(26.6)$ & $15,483(26.5)$ & $32,570(26.0)$ \\
\hline$\geq \$ 63,000$ & $32,856(32.5)$ & $22,340(31.0)$ & $18,462(31.6)$ & $37,849(30.2)$ \\
\hline \multicolumn{5}{|l|}{ Education ${ }^{\mathrm{b}}, \mathrm{n}(\%)$} \\
\hline$<7 \%$ & $24,573(24.3)$ & $16,103(22.3)$ & $13,238(22.6)$ & $27,009(21.5)$ \\
\hline $7-12.9 \%$ & $33,716(33.4)$ & $23,514(32.6)$ & $19,002(32.5)$ & $39,713(31.7)$ \\
\hline $13 \%-20.9 \%$ & $26,309(26.0)$ & $19,789(27.4)$ & 15,705 (26.9) & $34,564(27.6)$ \\
\hline$\geq 21 \%$ & $16,458(16.3)$ & $12,802(17.7)$ & $10,536(18.0)$ & $24,121(19.2)$ \\
\hline
\end{tabular}

reduce the number of patients that forgo needed health care. Our data suggests, however, that there are still significant disparities in cancer care between Medicaid patients and patients with private insurance.

Direct spending on cancer care in the US doubled between 1990 ( $\$ 63$ billion) and 2010 ( $\$ 125$ billion), and spending is estimated to rise to more than $\$ 173$ billion by $2020 .{ }^{28}$ Unfortunately, the benefits of increased cancer care funding has not been uniformly enjoyed by many Americans. Our data show that the rates of stage IV CRC have been increasing continuously since 2008. This is frustrating

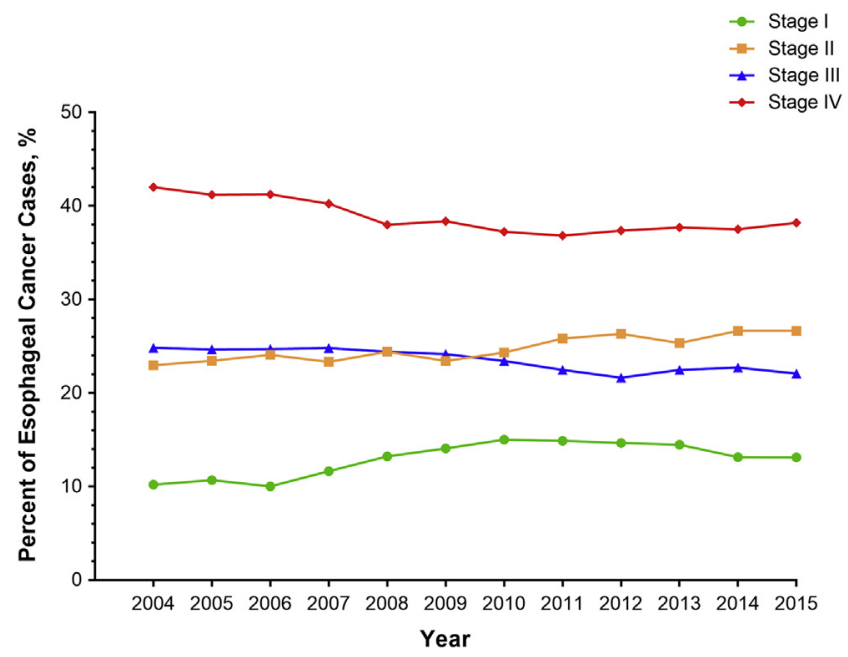

Fig. 1. Yearly trends in the percentage of patients diagnosed at each stage of disease, among patients with esophageal cancer. considering the available and effective screening tools for this disease, and highlights that further work is needed, including increasing equity in access to cancer prevention and care. A framework for eliminating CRC disparities was recently proposed, which includes preventive interventions that combine population-based outreach with office visit-based strategies. ${ }^{29}$ Electronic health records systems with automated monitoring and alerts of screening status are also currently used and have proven to increase uptake of screening programs. ${ }^{30}$ A recent study has shown that education plus tailored

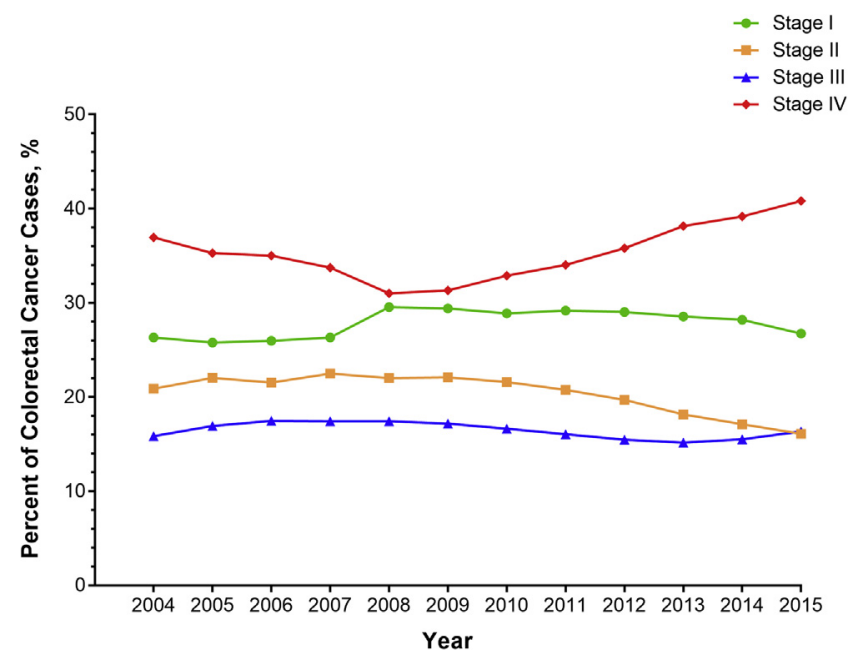

Fig. 2. Yearly trends in the percentage of patients diagnosed at each stage of disease, among patients with colorectal cancer. 
Table 3

Adjusted odds between race, residential income, travel distance, and primary insurance type with stage at diagnosis, stratified by esophageal and colorectal cancer.

\begin{tabular}{|c|c|c|c|c|c|c|}
\hline & \multicolumn{3}{|l|}{ Esophageal Cancer } & \multicolumn{3}{|l|}{ Colorectal Cancer } \\
\hline & $\begin{array}{l}\text { Stage II } \\
\text { OR }(95 \% \mathrm{CI})^{\mathrm{a}}\end{array}$ & $\begin{array}{l}\text { Stage III } \\
\text { OR }(95 \% \mathrm{CI})^{\mathrm{a}}\end{array}$ & $\begin{array}{l}\text { Stage IV } \\
\text { OR }(95 \% \mathrm{CI})^{\mathrm{a}}\end{array}$ & $\begin{array}{l}\text { Stage II } \\
\text { OR }(95 \% \mathrm{CI})^{\mathrm{a}}\end{array}$ & $\begin{array}{l}\text { Stage III } \\
\text { OR }(95 \% \mathrm{CI})^{\mathrm{a}}\end{array}$ & $\begin{array}{l}\text { Stage IV } \\
\text { OR }(95 \% \mathrm{CI})^{\mathrm{a}}\end{array}$ \\
\hline \multicolumn{7}{|l|}{ Race } \\
\hline White & REF & REF & REF & REF & REF & REF \\
\hline Black & $1.06(0.97,1.15)$ & $1.25(1.15,1.37)$ & $1.04(0.96,1.13)$ & $0.94(0.91,0.97)$ & $1.06(1.03,1.10)$ & $1.34(1.30,1.37)$ \\
\hline Other & $1.20(1.02,1.42)$ & $1.44(1.22,1.69)$ & $1.11(0.95,1.30)$ & $1.03(0.98,1.09)$ & $1.14(1.08,1.20)$ & $1.05(1.00,1.10)$ \\
\hline \multicolumn{7}{|l|}{ Primary insurance } \\
\hline Private & REF & REF & REF & REF & REF & REF \\
\hline Medicaid & $1.11(0.99,1.23)$ & $1.20(1.08,1.33)$ & $1.34(1.21,1.47)$ & $1.44(1.37,1.51)$ & $1.44(1.37,1.52)$ & $1.94(1.86,2.02)$ \\
\hline Medicare & $0.78(0.72,0.83)$ & $0.78(0.74,0.82)$ & $0.77(0.73,0.81)$ & $1.06(1.03,1.10)$ & $1.03(1.00,1.06)$ & $1.11(1.08,1.14)$ \\
\hline Uninsured & $1.12(0.96,1.32)$ & $1.53(1.31,1.78)$ & $1.99(1.72,2.31)$ & $2.05(1.92,2.17)$ & $1.90(1.78,2.02)$ & $2.33(2.21,2.46)$ \\
\hline \multicolumn{7}{|l|}{ Travel distance } \\
\hline$<4$ miles & REF & REF & REF & REF & REF & REF \\
\hline 4-7.9 miles & $0.98(0.91,1.05)$ & $1.00(0.93,1.08)$ & $0.92(0.86,0.99)$ & $0.97(0.94,1.00)$ & $0.98(0.95,1.01)$ & $0.99(0.96,1.01)$ \\
\hline $8-17.9$ miles & $0.94(0.88,1.01)$ & $0.99(0.92,1.06)$ & $0.83(0.78,0.89)$ & $0.97(0.94,0.99)$ & $0.98(0.95,1.01)$ & $0.99(0.97,1.02)$ \\
\hline$\geq 18$ miles & $0.78(0.73,0.83)$ & $0.79(0.74,0.84)$ & $0.50(0.47,0.53)$ & $0.99(0.96,1.02)$ & $1.00(0.97,1.03)$ & $1.20(1.17,1.23)$ \\
\hline \multicolumn{7}{|l|}{ Residential income } \\
\hline$<\$ 38,000$ & REF & REF & REF & REF & REF & REF \\
\hline$\$ 38,000-\$ 47,999$ & $0.99(0.92,1.07)$ & $1.03(0.96,1.12)$ & $1.02(0.94,1.09)$ & $0.95(0.92,0.98)$ & $0.94(0.90,0.97)$ & $0.93(0.90,0.96)$ \\
\hline$\$ 48,000-\$ 62,999$ & $0.96(0.88,1.04)$ & $0.98(0.90,1.06)$ & $0.93(0.86,1.00)$ & $0.95(0.92,0.98)$ & $0.95(0.91,0.98)$ & $0.94(0.91,0.97)$ \\
\hline$\geq \$ 63,000$ & $0.94(0.86,1.03)$ & $1.03(0.94,1.12)$ & $0.91(0.82,0.99)$ & $0.97(0.93,1.01)$ & $0.97(0.93,1.01)$ & $0.97(0.94,1.01)$ \\
\hline \multicolumn{7}{|l|}{ Education ${ }^{c}$} \\
\hline$<7 \%$ & REF & REF & REF & REF & REF & REF \\
\hline $7-12.9 \%$ & $0.99(0.93,1.06)$ & $1.02(0.95,1.09)$ & $1.05(0.98,1.11)$ & $1.07(1.04,1.10)$ & $1.06(1.02,1.09)$ & $1.05(1.03,1.08)$ \\
\hline $13 \%-20.9 \%$ & $0.97(0.90,1.05)$ & $1.03(0.95,1.11)$ & $1.05(0.97,1.13)$ & $1.14(1.11,1.18)$ & $1.09(1.05,1.13)$ & $1.10(1.07,1.13)$ \\
\hline$\geq 21 \%$ & $0.98(0.89,1.08)$ & $1.10(1.00,1.21)$ & $1.09(1.00,1.19)$ & $1.15(1.10,1.19)$ & $1.09(1.05,1.14)$ & $1.11(1.07,1.15)$ \\
\hline
\end{tabular}

Statistically significant results $(\mathrm{p}<0.05)$ are denoted in bold

a Adjusted for race, primary insurance, travel distance, residential income, education, age, sex, Charlson-Deyo comorbidity score, and year of diagnosis.

b Median residential household income estimated using the 2012 American Community Survey.

c Proportion of adults in patient's ZIP code who did not complete high school, measured in the 2012 American Community Survey.

navigation (in person or via phone) addressing individual barriers to screening are the most important components of any educational program aiming to increase adherence to CRC screening. ${ }^{31}$

This retrospective study has several limitations. The NCDB is not population-based registry, but rather identifies patients from 1500 commission-accredited cancer programs, and potentially limits the generalizability of our patient population. In addition, coding errors or different coding practices can occur among the different participant centers. Education and income are not patient-level measurements, but rather zip code-level covariates obtained from the 2012 American Community Survey and misclassification in these two disparity variables is possible. Finally, although screening for CRC is recommended for the general population we were not able to determine the rate of screening adherence in our study period.

\section{Conclusions}

The effect of racial and socioeconomic disparities on stage at diagnosis are more pronounced in adults with CRC, compared to esophageal cancer. Additionally, despite recommended screening guidelines and protocols, the rates of advanced CRC have increased between 2004 and 2015. Equity in access to screening and cancer care should be prioritized to reduce health disparities.

\section{Author contribution}

Francisco Schlottmann, Charles Gaber, Paula Strassle, Anthony Charles, and Marco G. Patti, conceived the study and helped with literature search and writing of the manuscript.

\section{Declaration of competing interest}

The authors have no conflict of interest.

\section{Appendix Table. Sensitivity analysis restricted to colorectal cancer patients $\geq \mathbf{5 0}$ years old}

\begin{tabular}{|c|c|c|c|}
\hline & $\begin{array}{l}\text { Stage II } \\
\text { OR }(95 \% \mathrm{CI})^{\mathrm{a}}\end{array}$ & $\begin{array}{l}\text { Stage III } \\
\text { OR }(95 \% \mathrm{CI})^{\mathrm{a}}\end{array}$ & $\begin{array}{l}\text { Stage IV } \\
\text { OR }(95 \% \mathrm{CI})^{\mathrm{a}}\end{array}$ \\
\hline \multicolumn{4}{|l|}{ Race } \\
\hline White & REF & REF & REF \\
\hline Black & $0.94(0.91,0.97)$ & $1.04(1.00,1.08)$ & $1.34(1.30,1.38)$ \\
\hline Other & $1.00(0.95,1.06)$ & $1.12(1.05,1.19)$ & $1.02(0.97,1.07)$ \\
\hline \multicolumn{4}{|l|}{ Primary insurance } \\
\hline Private & REF & REF & REF \\
\hline Medicaid & $1.42(1.34,1.50)$ & $1.43(1.35,1.51)$ & $1.93(1.85,2.03)$ \\
\hline Medicare & $1.07(1.04,1.10)$ & $1.03(1.00,1.07)$ & $1.12(1.10,1.15)$ \\
\hline Uninsured & $2.11(1.97,2.26)$ & $1.93(1.79,2.07)$ & $2.56(2.41,2.72)$ \\
\hline \multicolumn{4}{|l|}{ Travel distance } \\
\hline$<4$ miles & REF & REF & REF \\
\hline 4-7.9 miles & $0.96(0.94,0.99)$ & $0.98(0.95,1.01)$ & $0.98(0.95,1.00)$ \\
\hline $8-17.9$ miles & $0.96(0.93,0.99)$ & $0.98(0.95,1.01)$ & $0.98(0.95,1.00)$ \\
\hline$\geq 18$ miles & $0.98(0.96,1.01)$ & $1.01(0.98,1.04)$ & $1.16(1.13,1.19)$ \\
\hline \multicolumn{4}{|l|}{ Residential income ${ }^{b}$} \\
\hline$<\$ 38,000$ & REF & REF & REF \\
\hline$\$ 38,000-\$ 47,999$ & $0.94(0.91,0.98)$ & $0.93(0.90,0.97)$ & $0.93(0.90,0.96)$ \\
\hline$\$ 48,000-\$ 62,999$ & $0.95(0.91,0.98)$ & $0.95(0.91,0.98)$ & $0.95(0.92,0.98)$ \\
\hline$\geq \$ 63,000$ & $0.97(0.93,1.01)$ & $0.97(0.92,1.01)$ & $0.98(0.95,1.02)$ \\
\hline \multicolumn{4}{|l|}{ Education ${ }^{c}$} \\
\hline$<7 \%$ & REF & REF & REF \\
\hline $7-12.9 \%$ & $1.07(1.03,1.10)$ & $1.06(1.03,1.10)$ & $1.06(1.04,1.09)$ \\
\hline $13 \%-20.9 \%$ & $1.14(1.10,1.18)$ & $1.10(1.06,1.14)$ & $1.12(1.08,1.15)$ \\
\hline$\geq 21 \%$ & $1.14(1.10,1.19)$ & $1.09(1.04,1.15)$ & $1.13(1.09,1.17)$ \\
\hline
\end{tabular}

Statistically significant results $(\mathrm{p}<0.05)$ are denoted in bold

a Adjusted for race, primary insurance, travel distance, residential income, education, age, sex, Charlson-Deyo comorbidity score, and year of diagnosis.

b Median residential household income estimated using the 2012 American Community Survey.

c Proportion of adults in patient's ZIP code who did not complete high school, measured in the 2012 American Community Survey. 


\section{References}

1. Siegel RL, Miller KD, Jemal A. Cancer statistics, 2017. CA A Cancer J Clin. 2017;67(1):7-30.

2. Singh GK, Daus GP, Allender M, et al. Social determinants of health in the United States: addressing major health inequality trends for the nation, 19352016. Int J MCH AIDS. 2017;6(2):139-164.

3. Singh GK, Jemal A. Socioeconomic and racial/ethnic disparities in cancer mortality, incidence, and survival in the United States, 1950-2014: over six decades of changing patterns and widening inequalities.J Environ Public Health. 2017;2017, 2819372.

4. Centers for Disease Control and Prevention (CDC). Vital signs: health insurance coverage and health care utilization - United States, 2006-2009 and JanuaryMarch 2010. MMWR Morb Mortal Wkly Rep. 2010;59(44):1448-1454.

5. Hendren S, Chin N, Fisher S, et al. Patients' barriers to receipt of cancer care, and factors associated with needing more assistance from a patient navigator. J Natl Med Assoc. 2011;103(8):701-710.

6. Siegel RL, Miller KD, Fedewa SA, et al. Colorectal cancer statistics, 2017. CA Cancer J Clin. 2017;67(3):177-193.

7. National Cancer Institute. Surveillance, epidemiology, and end results program. Cancer stat facts: esophageal cancer. Available at: https://seer.cancer.gov/ statfacts/html/esoph.html. Accessed May 4, 2018.

8. Hur C, Miller M, Kong CY, et al. Trends in esophageal adenocarcinoma incidence and mortality. Cancer. 2013;119(6):1149-1158.

9. Arnold M, Laversanne M, Brown LM, Devesa SS, Bray F. Predicting the future burden of esophageal cancer by histological subtype: international trends in incidence up to 2030. Am J Gastroenterol. 2017;112(8):1247-1255.

10. National Cancer Institute. Surveillance, epidemiology, and end results program. Cancer stat facts: colorectal cancer. Available at: https://seer.cancer.gov/ statfacts/html/colorect.html. Accessed May 4, 2018.

11. Aizer AA, Wilhite TJ, Chen MH, et al. Lack of reduction in racial disparities in cancer-specific mortality over a 20-year period. Cancer. 2014;120(10): 1532-1539.

12. Gonzales M, Qeadan F, Mishra SI, Rajput A, Hoffman RM. Racial-ethnic disparities in late-stage colorectal cancer among hispanics and non-hispanic whites of New Mexico. Hisp Health Care Int. 2017;15(4):180-188.

13. Arshad HMS, Kabir C, Tetangco E, Shah N, Raddawi H. Racial disparities in clinical presentation and survival times among young-onset colorectal adenocarcinoma. Dig Dis Sci. 2017;62(9):2526-2531.

14. Ellis L, Canchola AJ, Spiegel D, Ladabaum U, Haile R, Gomez SL. Racial and ethnic disparities in cancer survival: the contribution of tumor, sociodemographic, institutional, and neighborhood characteristics. J Clin Oncol. 2018;36(1):25-33.

15. Augustus GJ, Ellis NA. Colorectal cancer disparity in African Americans: risk factors and carcinogenic mechanisms. Am J Pathol. 2018;188(2):291-303.

16. Boulware LE, Cooper LA, Ratner LE, LaVeist TA, Powe NR. Race and trust in the health care system. Public Health Rep. 2003;118(4):358-365.
17. Kennedy BR, Mathis CC, Woods AK. African Americans and their distrust of the health care system: healthcare for diverse populations. I Cult Divers. 2007; 14(2):56-60.

18. Mandelblatt J, Andrews H, Kao R, Wallace R, Kerner J. The late-stage diagnosis of colorectal cancer: demographic and socioeconomic factors. Am J Public Health. 1996;86(12):1794-1797.

19. Clegg LX, Reichman ME, Miller BA, et al. Impact of socioeconomic status on cancer incidence and stage at diagnosis: selected findings from the surveillance, epidemiology, and end results: national longitudinal mortality study. Cancer Causes Control. 2009;20(4):417-435.

20. Zahnd WE, Fogleman AJ, Jenkins WD. Rural-urban disparities in stage of diagnosis among cancers with preventive opportunities. Am J Prev Med. 2018;54(5):688-698.

21. Anderson AE, Henry KA, Samadder NJ, Merrill RM, Kinney AY. Rural vs urban residence affects risk-appropriate colorectal cancer screening. Clin Gastroenterol Hepatol. 2013;11(5):526-533.

22. Parikh-Patel A, Morris CR, Kizer KW. Disparities in quality of cancer care: the role of health insurance and population demographics. Medicine (Baltim). 2017;96(50), e9125.

23. Tantraworasin A, Taioli E, Liu B, Flores RM, Kaufman AJ. The influence of insurance type on stage at presentation, treatment, and survival between Asian American and non-Hispanic White lung cancer patients. Cancer Med. 2018;7(5):1612-1629.

24. Hsu CD, Wang X, Habif Jr DV, Ma CX, Johnson KJ. Breast cancer stage variation and survival in association with insurance status and sociodemographic factors in US women 18 to 64 years old. Cancer. 2017;123(16):3125-3131.

25. Abdelsattar ZM, Hendren S, Wong SL. The impact of health insurance on cance care in disadvantaged communities. Cancer. 2017;123(7):1219-1227.

26. Obama B. United States health care reform: progress to date and next steps. J Am Med Assoc. 2016;316(5):525-532.

27. Health Reform Monitoring Survey. Taking stock: Health insurance coverage under the ACA as of September 2014. Washington, DC: Urban Institute; 2014 Available at: http://hrms.urban.org/briefs/Health-Insurance-Coverage-underthe-ACA-as-of-September-2014.html. Accessed July 4, 2018.

28. American Society of Clinical Oncology. The state of cancer care in America 2014: a report by the American Society of Clinical Oncology. J Oncol Pract. 2014;10(2):119-142.

29. Carethers JM, Doubeni CA. Causes of socioeconomic disparities in colorecta cancer and intervention framework and strategies. Gastroenterology. 2019. https://doi.org/10.1053/j.gastro.2019.10.029. epub ahead of print.

30. Guiriguet C, Muñoz-Ortiz L, Burón A et al. Alerts in electronic medical records to promote a colorectal cancer screening programme: a cluster randomised controlled trial in primary care. Br J Gen Pract. 2016;66(648):483-490.

31. Menon U, Szalacha LA, Kue J, et al. Effects of a community-to-clinic navigation intervention on colorectal cancer screening among underserved people. Ann Behav Med. 2019. https://doi.org/10.1093/abm/kaz049. epub ahead of print. 